\title{
Effect of aerosol particle size on bronchodilatation with nebulised terbutaline in asthmatic subjects
}

\author{
MICHELLE M CLAY, DEMETRI PAVIA, STEWART W CLARKE
}

From the Department of Thoracic Medicine, Royal Free Hospital, London

ABSTRACT The bronchodilatation achieved by the $\beta_{2}$ agonist terbutaline sulphate given as nebulised aerosol from different devices has been measured in seven patients with mild asthma (mean FEV F $_{1}$ $76 \%$ predicted) over two hours after inhalation. The subjects were studied on four occasions. On three visits they received $2.5 \mathrm{mg}$ terbutaline delivered from three different types of nebuliser, selected $\stackrel{\odot}{\perp}$ on the basis of the size distribution of the aerosols generated; and on a fourth (control) visit no 은 aerosol was given. The size distributions of the aerosols expressed in terms of their mass median diameter (MMD) were: A: MMD $1.8 \mu \mathrm{m}$; B: $4.6 \mu \mathrm{m}$; C: $10.3 \mu \mathrm{m}$. The aerosols were given under controlled conditions of respiratory rate and tidal volume to minimise intertreatment variation. Bronchodilator response was assessed by changes in $F_{1} V_{1}$, forced vital capacity (FVC), peak $\vec{\emptyset}_{\mathscr{O}}$ expiratory flow (PEF), and maximal flow after expiration of $50 \%$ and $75 \%$ FVC $\left(\dot{V}_{\max }{ }_{50}, \dot{V}_{\max }{ }_{25}\right)$ ? from baseline (before aerosol) and control run values. For each pulmonary function index all three aerosols gave significantly better improvement over baseline than was seen in the control $(p<0.05)$ \& and had an equipotent effect on FEV, FVC, and PEF. Aerosol A (MMD $1.8 \mu \mathrm{m}$ ) produced significantly greater improvements in $\dot{V} \max _{50}$ and $\dot{V} \max _{25}$ than did $B$ or $C(p<0.05)$. These results $\frac{\mathscr{O}}{\mathbb{D}}$ suggest that for $\beta_{2}$ agonists small aerosols (MMD $<2 \mu \mathrm{m}$ ) might be advantageous in the treatment of asthma.

Aerosol size is the most important factor determining the site of aerosol deposition within the respiratory tract. $^{1}$ During inhalation aerosols are filtered out from the airstream according to their size. Few particles larger than $10 \mu \mathrm{m}$ pass the larynx. ${ }^{2}$ Particles of 5-10 $\mu \mathrm{m}$ have a high probability of being deposited in the large airways, particularly at bifurcations. Particles smaller than $5 \mu \mathrm{m}$ may penetrate deeper into the lung but less so in the presence of airways obstruction, when particles smaller than $2 \mu \mathrm{m}$ may be required. Aerosol particles smaller than $0.5 \mu \mathrm{m}$, however, have a high airborne stability and may be exhaled without being deposited at all. ${ }^{3}$

Nebulisers are frequently used to deliver bronchodilator aerosols, and previous work has shown that there is considerable variation between makes and driving conditions that affects the size of the particles released. ${ }^{4}$ Given that adrenoreceptors may exist in higher concentrations in the small airways, ${ }^{56}$ we

Address for reprint requests: Miss Michelle M Clay, Department of Thoracic Medicine, Royal Free Hospital, London NW3 2QG.

Accepted 29 November 1985 have compared the bronchodilator effect of ter butaline sulpate (Bricanyl respirator solution, Astrac Pharmaceuticals) using three commercially availablen nebulisers that we have previously shown to differ in terms of the size distribution of the aerosols pro-3. duced, the mass median diameters being $1.8,4.6$, and $10.3 \mu \mathrm{m}$.

Methods

PATIENTS

Eleven asthmatic patients, eligible to participatên because they could show an increase in $\mathrm{FEV}_{1}$ of at least $15 \%$ after inhalation of $500 \mu \mathrm{g}$ terbutaline sulı phate from a metered dose inhaler, entered the trial $\sigma$ All were regularly taking $\beta_{2}$ agonist aerosols, which were stopped 12 hours before each study. Of the 1 ? subjects, four were withdrawn because their baselines FEV $_{1}$ varied by over $15 \%$ between visits. Of the remaining seven subjects, six were male. Their meanb age was 45 years (range $23-70$ ) and their mean base $\vec{D}$ line $\mathrm{FEV}_{1}$ was $76 \%$ of the values predicted for thei age, height and sex. Three were lifetime non-smokers and the others either current smokers or ex-smokerse 
with an average smoking history of 23 pack years. Informed written consent was obtained from each subject before the study and permission for the study was obtained from the local ethical committee.

\section{STUDY DESIGN}

Each subject was studied on four occasions, each visit starting at the same time of day. On arrival the subjects rested for five minutes and then baseline pulmonary function and pulse were measured. The indices of pulmonary function recorded were $\mathrm{FEV}_{1}$, forced vital capacity (FVC), and maximal flow rates after expiration of $50 \%$ and $75 \%$ FVC (V́max 50 and V'max ${ }_{25}$ ) interpreted from flow-volume curves obtained from an Ohio dry spirometer linked to a Gould X-Y plotter. Peak expiratory flow (PEF) was measured with a Wright peak flow meter. All measurements were taken from the best of three technically acceptable results. Vंmax ${ }_{50}$ and $\dot{V} \max _{25}$ were taken as indicators of small airways function and were all measured after completion of the four studies on the basis of the largest FVC obtained for each subject, thereby enabling the flow rates to be measured at the same lung volumes. After baseline measurements had been made the subjects were randomly allocated to one of four groups, receiving $2.5 \mathrm{mg}$ terbutaline sulphate (diluted to $4 \mathrm{ml}$ with physiological saline) delivered via one of the three different types of nebuliser, A, B, and C, or acting as controls receiving no aerosol.

Pulse and pulmonary function measurements were repeated $30,60,90$, and 120 minutes after administration of aerosol.

\section{NEBULISER SELECTION AND AEROSOL}

\section{ADMINISTRATION}

Three different makes of nebuliser operated with three different flow rates of compressed air were used to generate the three aerosols studied. The selection of nebuliser make and operating conditions was made on the basis of previous work. ${ }^{4}$ Each nebuliser was independently characterised before use for the size distribution of the aerosols released with a Malvern Laser Particle Sizer by the technique previously described. ${ }^{4}$ Aerosol A was generated by a Turret neb- uliser operated at a flow rate of $81 \mathrm{~min}^{-1}$ with compressed air. In these circumstances the aerosol produced has an MMD of $1.8 \mu \mathrm{m}$ and over $80 \%$ of the aerosol mass is contained in droplets smaller than 5 $\mu \mathrm{m}$. Aerosol B was generated by an Upmist nebuliser driven at $61 \mathrm{~min}^{-1}$ with compressed air. Under these operating conditions the aerosol produced has an MMD of $4.6 \mu \mathrm{m}$ with about $50 \%$ of the mass of aerosol contained in droplets smaller than $5 \mu \mathrm{m}$. Aerosol $C$ was generated by an Inspiron Mini-neb nebuliser driven at $41 \mathrm{~min}^{-1}$ by compressed air. The MMD of the aerosol released has been found to be $10.3 \mu \mathrm{m}$ with $20 \%$ of the mass of aerosol smaller than $5 \mu \mathrm{m}$.

The subjects were seated with their nostrils occluded by a noseclip. The aerosols were inhaled through a mouthpiece directly from the nebuliser under strictly controlled conditions to minimise intertreatment variation. The subjects synchronised their breathing to an audible signal generated by an electronic device, which facilitated a breathing pattern of 14 breaths a minute with inspiration lasting one third of the respiratory cycle. In addition, they inhaled a fixed volume $(700 \mathrm{ml})$ with each breath regulated by the use of Voldyne Volumetric Exerciser (Cheeseborough Pond Ltd), thereby ensuring a reproducible inhalation pattern between aerosol studies.

The volume of aerosol produced during nebulisation was determined by weighing the device before and after, and the duration of nebulisation itself was timed with a stopwatch.

\section{STATISTICS}

Non-parametric statistics were applied to the experimental results. These were the Friedman analyses of variance and the Wilcoxon rank sum test for paired and unpaired data. ${ }^{7}$

\section{Results}

There was no significant difference between the mean (SE) volumes of aerosol generated by the three nebulisers: Aerosol A $1.84(0.12) \mathrm{ml}$; aerosol B $1.70(0.03)$ $\mathrm{ml}$; aerosol C $1.88(0.10) \mathrm{ml}$. The duration of nebulisation, however, varied significantly between the three studies as a result of the flow rates used to drive

Table 1 Baseline pulmonary function (means (SE)) on each of the four study days

\begin{tabular}{|c|c|c|c|c|}
\hline & \multirow[t]{2}{*}{ Control } & \multicolumn{3}{|l|}{ Nebuliser } \\
\hline & & (A) & (B) & (C) \\
\hline $\begin{array}{l}F E V_{1}(1) \\
F V C(1) \\
\text { PEF }\left(1 \min ^{-1}\right) \\
\operatorname{Vmax}_{50}\left(1 \mathrm{~s}^{-1}\right) \\
\operatorname{Vmax}_{25}\left(1 \mathrm{~s}^{-1}\right)\end{array}$ & $\begin{array}{c}2.61(0.31) \\
3.90(0.53) \\
400(43) \\
1.75(0.33) \\
0.38(0.09)\end{array}$ & $\begin{array}{c}2.64(0.35) \\
3.85(0.55) \\
399(43) \\
1.56(0.31) \\
0.35(0.14)\end{array}$ & $\begin{array}{c}2.61(0.35) \\
3.94(0.53) \\
400(38) \\
1.73(0.34) \\
0.39(0.12)\end{array}$ & $\begin{array}{r}2.47(0.33) \\
3.85(0.56) \\
387(39) \\
1.54(0.30) \\
0.36(0.11)\end{array}$ \\
\hline
\end{tabular}

FVC-forced vital capacity; PEF-peak expiratory flow; $\max _{50}, \operatorname{Vmax}_{25}$-maximal flow after expiration of $50 \%$ and $75 \%$ FVC. 


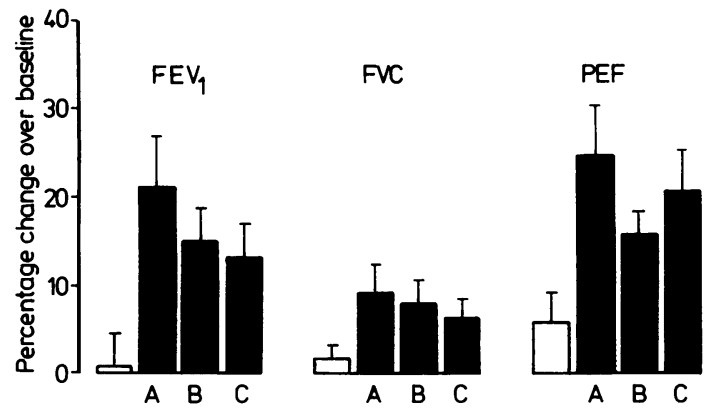

Fig 1 Mean percentage improvements in $F E V_{1}$, forced vital capacity $(F V C)$, and peak expiratory flow (PEF) one hour after inhalation of terbutaline with the three nebulisers $(A-C)$ and also at one hour in the control run (unhatched). Bars represent $1 S E$.

the nebulisers: aerosol A $5.85(0.28)$ minutes; aerosol B $8.90(0.72)$ minutes; aerosol C 16.42 (1.17) minutes $(\mathrm{p}<0.05)$.

Table 1 shows the mean (SE) baseline values for each of the pulmonary function indices on the four study days, between which there was no significant difference.

Improvements over baseline values for $\mathrm{FEV}_{1}$, FVC, and PEF one hour after inhalation of the three aerosols and also in the control run are shown in figure 1; all were significantly better after aerosol

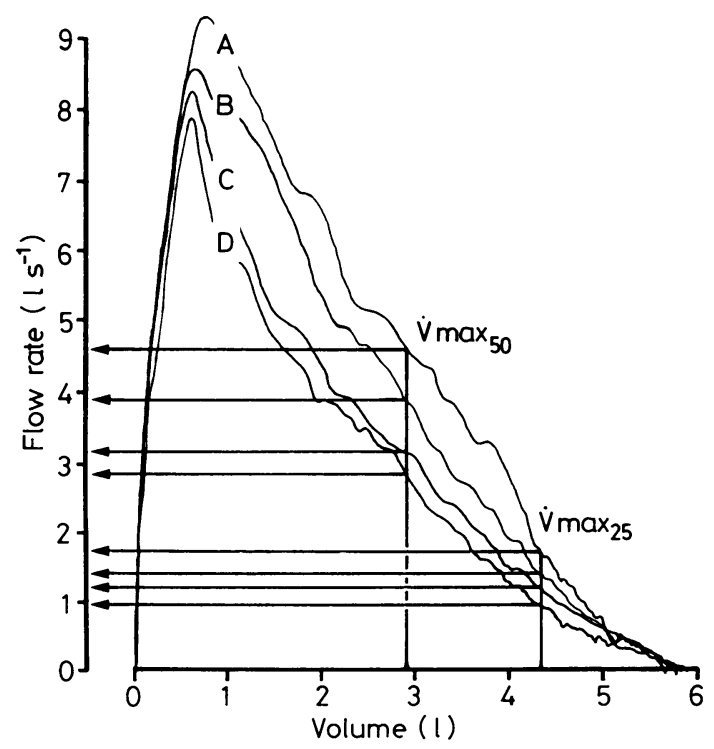

Fig 2 Maximal expiratory flow-volume curves of one subject one hour after inhalation of terbutaline with the three nebulisers $(A-C)$ and also in the control run $(D)$.

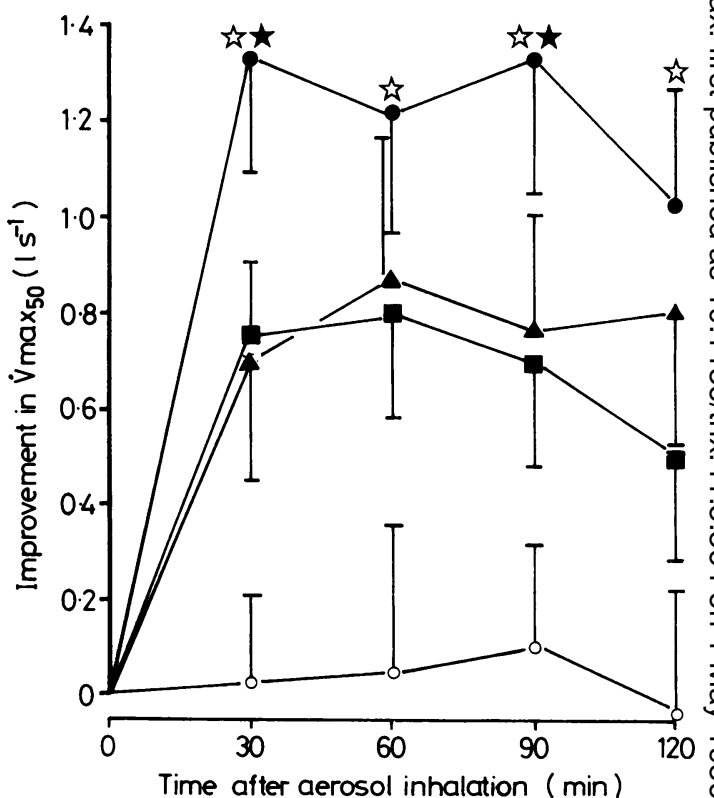

Fig 3 Mean improvements in maximal flow after expiration of $50 \% \mathrm{FVC}\left(\dot{V}_{\max }{ }_{50}\right)$ over baseline after inhalation of terbutaline with three nebulisers ( -nebuliser $A$,

$\Delta$-nebuliser $B ;-$ nebuliser $C$ ) and after control with no aerosol $(\bigcirc)$. Open asterisks indicate that $A$ is significantly better than $C(p<0.05)$ and closed asterisks that $A$ is significantly better than $B(p<0.05)$.

inhalation than in the control run $(\mathrm{p}<0.05)$ 贵 Although the mean values show the greatest. improvement after inhalation of aerosol A, this difference achieved significance only at one hour fot PEF $(\mathrm{p}<0.05)$.

Figure 2 shows the flow-volume curves obtained in one subject one hour after the three aerosols and alsoi at one hour in the control run. The figure shows as gradation in improvement in $\operatorname{Vmax}_{50}$ and $\dot{\mathrm{V}} \max _{20}$ with decreasing aerosol size $(\mathrm{A}>\mathrm{B}>\mathrm{C}>$ control $)$ ?

For the group of seven subjects taken as a whole figure 3 shows the mean (SE) improvements in $\dot{V} \max _{50}$ over baseline values throughout the two houñ observation period. Aerosol A achieved better bronn chodilatation than either aerosol B or aerosol \& throughout, and this difference was significant $(\mathrm{p}-$ 0.05 ) during the entire two hours when aerosol $A$ was compared with $\mathrm{C}$ and at 30 and 90 minutes when if was compared with aerosol $\mathrm{B}$.

There was no significant difference between aerosols $B$ and $C$ but the values obtained with all threg were consistently better than control values ( $p$ 0.05 ). Figure 4 shows the improvements in $\operatorname{Vmax}_{2} \frac{\rho}{\Phi}$ during the two hour observation period. Aerosol $\mathbb{P}$ achieved better bronchodilatation than either $\mathbf{B}$ or $\mathbb{Q}^{0}$ 


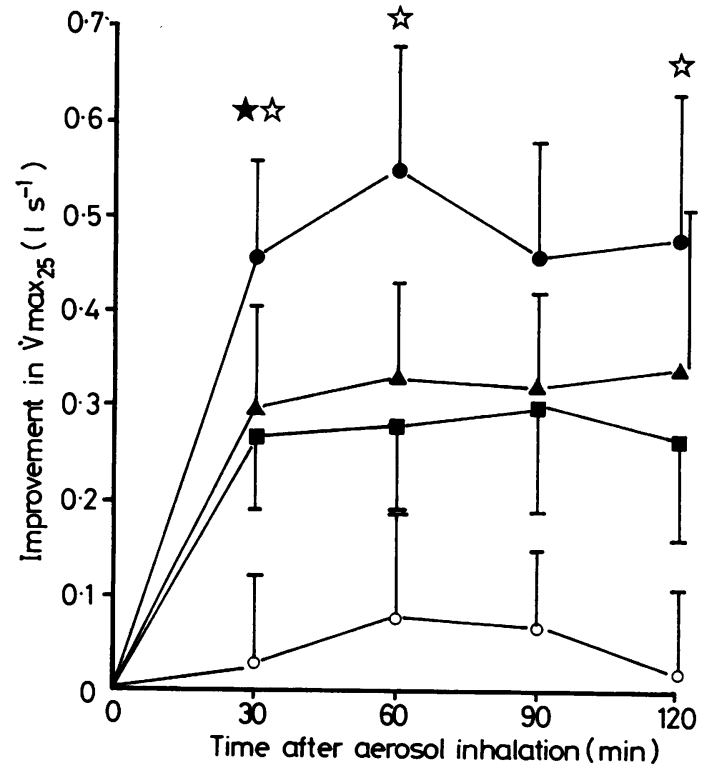

Fig 4 Mean improvements in maximal flow after expiration of $75 \%$ FVC $\left(\dot{V}_{\max }\right.$ ) $)$ over baseline after inhalation of terbutaline with three nebulisers (O-nebuliser $A$;

$\Delta-$ nebuliser $B$; $\square$-nebuliser $C$ ) and after control without aerosol ( $O$ ). Open asterisks indicate that $A$ is significantly better than $C(p<0.05)$ and closed asterisks that $A$ is significantly better than $B(p<0.05)$.

but this attained significance only at $\mathbf{3 0}$ minutes when it was compared with aerosol B and at 30,60, and 120 minutes when it was compared with aerosol $\mathrm{C}$. The results with all three aerosols were significantly better than control values throughout the two hour observation period $(p<0.05)$.

There was no significant difference between the pulse rates obtained during the hours after inhalation of any of the aerosols and the control pulse rates (table 2).

\section{Discussion}

This study set out to compare the efficacies of three nebulised aerosols of the bronchodilator terbutaline. Although the three aerosols were generated by three different makes of nebuliser, because the volume of aerosol and inhalation mode were kept constant between treatments we may reasonably assume that any observed differences were the result of differences in the quality of the aerosols themselves. The aerosols were selected for differences in their size distributions that would influence the site and amount of deposition in the lung. Aerosol A, with an MMD of $1.8 \mu \mathrm{m}$, would be expected to deposit more in the lung than aerosols $\mathrm{B}$ or $\mathrm{C}$. We believe that the results offer convincing evidence that the bronchodilator efficacy of terbutaline is directly affected by the aerosol size.

Surprisingly little work has been carried out to examine whether there is any therapeutic advantage in the use of bronchodilator aerosols of small particle size. As the distribution of receptors within the lung is elucidated it becomes possible to "target" an aerosol towards a particular region of the respiratory tract. Krieger $^{8}$ and Rees and Clark, ${ }^{9}$ using pressurised aerosols from metered dose inhalers, were able to show that small particles resulted in better bronchodilatation than large particles, and similar observations were made by Godfrey et al for sodium cromoglycate in the prevention of exercise induced asthma. $^{10}$ In the case of nebulised aerosols, Keighley ${ }^{11}$ failed to find such an effect, and similarly Hadfield $e t a^{12}$ found no therapeutic advantage in driving nebulisers at a higher flow rate that would reduce aerosol size. In both these studies, however, the inhalation mode was not controlled and consequently any differences between the aerosols may have been masked. Furthermore, these studies were limited to examination of large airways function $\left(\mathrm{FEV}_{1}, \mathrm{FVC}\right.$, and PEF) and indices of small airways function were not measured.

Knudson et $a^{13}$ showed that the use of maximal expiratory flow-volume curves facilitated sensitive examination of small airways function, enabling abnormalities due to increased airways resistance to be measured. Using this technique combined with a controlled and reproducible aerosol administration procedure, we have been able to show that a terbutaline aerosol with an MMD of about $2 \mu \mathrm{m}$ with

Table 2 Varation in heart rate (means with standard errors in parentheses)

\begin{tabular}{|c|c|c|c|c|}
\hline \multirow{2}{*}{$\begin{array}{l}\text { Minutes after } \\
\text { inhalation }\end{array}$} & \multirow[t]{2}{*}{ Control } & \multicolumn{3}{|l|}{ Nebuliser } \\
\hline & & $(A)$ & $(B)$ & (C) \\
\hline $\begin{array}{l}\text { Baseline } \\
30 \\
60 \\
90 \\
120\end{array}$ & $\begin{array}{l}74.8(3.2) \\
74.3(3.4) \\
75.1(3.3) \\
75.4(3.8) \\
75.4(4.7)\end{array}$ & $\begin{array}{l}77.1(5.5) \\
75.7(5.3) \\
76.2(5.7) \\
73.1(5.0) \\
75.1(5.4)\end{array}$ & $\begin{array}{l}76.5(4.6) \\
76.5(5.4) \\
74.0(5.3) \\
76.6(4.8) \\
72.0(5.4)\end{array}$ & $\begin{array}{l}74.1(5.2) \\
72.6(5.0) \\
75.6(4.2) \\
72.6(4.1) \\
72.3(3.9)\end{array}$ \\
\hline
\end{tabular}


the bulk of the particles smaller than $5 \mu \mathrm{m}$ caused more dilatation of the small airways than aerosols of larger particles. We may reasonably assume that the aerosol penetrates to the small airways and exerts a topical effect on the adrenoreceptors there. The effect might have been more pronounced had subjects with more severe bronchoconstriction been studied, but such subjects were necessarily excluded here because their baseline pulmonary function values varied too much between studies to permit differences in response to be attributed to aerosol quality alone.

In this study half the usual $5 \mathrm{mg}$ dose of terbutaline was used, in an attempt to differentiate between the effects of the three aerosol sizes without saturating the adrenoreceptors. In fact, maximal bronchodilatation might well have been achieved with much smaller doses, as noted by Ruffin et al in the case of fenoterol, ${ }^{14}$ and the differences might have been emphasised had an even smaller dose been used. Douglas et $a l^{15}$ were, however, unable to show any differences in the dose-response curves obtained with nebulised rimiterol under varying nebulising conditions that would affect aerosol size, though the aerosols were not inhaled under controlled conditions and small airways function was not assessed. Further work is required to construct dose-response curves for aerosols of different sized particles under standardised conditions to establish whether there is a therapeutic advantage to be gained from targeting different types of therapeutic aerosols towards particular regions of the lung.

In the presence of airways obstruction aerosols of a particular particle size penetrate less deeply. To achieve the same depth of penetration particle size has to be reduced. ${ }^{16}$ It is therefore possible that an aerosol with an MMD of $5 \mu \mathrm{m}$ or greater may be deposited more and more centrally with increasing severity of airways obstruction and ultimately fail to penetrate the airways at all; in such circumstances an aerosol with smaller particles might still penetrate the airways and be effective. This possibility has not hitherto been considered and it could account for the failure of nebuliser treatment that may occur in acute severe asthma.

We wish to thank the Peter Samuel fund of the Royal Free Hospital and Astra Pharmaceuticals Ltd for financial support for the study. We would also like to thank Miss Eleanor Hogg, Drs Ann Millar, and
Monica Spiteri for assistance with selection of patients.

\section{References}

1 Heyder J, Gebhart J, Stahlhofen W. Inhalation of aero $\overline{\bar{S}}$ sols: particle deposition and retention. In: Willeke K, edळ Generation of aerosols. Ann Arbor: Ann Arbor Science्ट Publishers, 1980.

2 Swift DL, Proctor DF. Human respiratory deposition of particles during oronasal breathing. Atmos Environ 1982;16:2279-82.

3 Agnew JE. Physical properties and mechanisms of depoळ sition of aerosols. In: Clarke SW, Pavia D, ed. Aerosols and the lung. London: Butterworths, 1984.

4 Clay MM, Pavia D, Newman SP, Clarke SW. Factors influencing the size distribution of aerosols from jetr nebulisers. Thorax 1983;38:755-9.

5 Hensley MJ, O'Cain CF, McFadden ER, Ingram RIP jun. Distribution of bronchodilatation in normal subo jects: beta agonists versus atropine. $J$ Appl PhysioP. Respirat Environ Exercise Physiol 1978;45:778-82.

6 Barnes PJ, Basbaum CB, Nadel JA, Robert JM. Loca不 isation of beta-adrenoreceptors in the mammalian lung by light microscopic autoradiography. Nature 19820 229:444-7.

7 Siegel S. Non parametric statistics for behavioural sciences. Tokyo: McGraw-Hill Kogakusha, 1956.

8 Krieger E. Effects of various particle sizes in aerosos treatment with a beta-adrenergic agent. In: Straubel MP ed. Aerosol in Naturiwisienschaft, Medizin und Technik Chemie der Unweltaerosole. Bad Solen: Klinisches Sana torium Traufnitz, 1975:150-9.

9 Rees BJ, Clark TJH. The importance of particle size it response to inhaled bronchodilators. Eur $J$ Respir $D$ 1982;suppl 119:73-8.

10 Godfrey S, Zeidifarde E, Brown K, Bell JH. The possib site of action of sodium cromoglycate assessed by exercise challenge. Clin Sci Mol Med 1974;46:265-72.

11 Keighley JFH. Response to sympathomimetic aeroso of different particle size in subjects with chronic bronche tis. Am Rev Respir Dis 1968;98:879-82.

12 Hadfield JW, Lowe G, Windebank WJ, Bateman JRMB Is gas flow rate clinically important for nebuliser the apy? [abstract]. Thorax 1984;39:240.

13 Knudson RJ, Burrows B, Lebowitz MD. The maxima expiratory flow volume curve: its use in the detection of ventilatory abnormalities in a population study. Am Rey Respir Dis 1976;114:871-9.

14 Ruffin RE, Obminski G, Newhouse MT. Aerosol admin istration by IPPB: lowest effective dose. Thoras 1978;33:689-93.

15 Douglas JG, Leslie MJ, Crompton GK, Grant IWB. ह5 the flow rate used to drive a jet nebuliser clinicalle important? Br Med J 1985;290:29.

16 Pavia D, Thomson ML, Clarke SW, Shannon HS. Effect of lung function and mode of inhalation on penetratiof of aerosol into the human lung. Thorax 1977;32:194-7 